Available online on 15.07.2016 at http://jddtonline.info
Journal of Drug Delivery and Therapeutics
An International Peer Reviewed Journal
Open access to Pharmaceutical and Medical research
ㄷ 2016, publisher and licensee JDDT, This is an Open Access article which permits unrestricted non-commercial use, provided the original
work is properly cited

\title{
FORMULATION OF AN INSITU FORMING INJECTABLE SUSTAINED RELEASE SPONGE OF GRANISETRON HYDROCHLORIDE
}

\author{
Reshma Mirajkar*, Renuka Jagtap, Ashwini Madgulkar \\ Department of Pharmaceutics, AISSMS College of Pharmacy, Kennedy Road, Pune 411001, Maharashtra, INDIA \\ Received 02 June 2016; Review Completed 30 June 2016; Accepted 30 June 2016, Available online 15 July 2016
}

\begin{abstract}
The overall aim of this work was to develop sustained release parenteral drug delivery system involving formation of an insitu sponge of anti-emetic drug typically co-administered in chemotherapy induced nausea and vomiting. The study involved formulation of the drug Granisetron Hydrochloride in a sponge forming gelatin matrix as a dry powder for reconstitution into a suspension to be injected into the body forming a sponge insitu intended to release the drug over a period of 5 days. The formulation was prepared by the method cryogelation and optimised using gelatin5\% as a sponge forming polymer, crosslinking agent glutaraldehyde $0.3 \%$, sustained release retardant Hydroxypropylmethyl cellulose K100M 1\% (HPMC K100M) and suspending agent sodium carboxymethylcellulose $1 \%(\mathrm{NaCMC})$ to form a solution intended to be administered subcutaneously. The formulation was evaluated for all prerequisites of parenteral and other parameters of gelatin matrix like swelling index, surface scanning microscopy for injectable suspension, sedimentation study, particle size, zeta measurement, in-vitro drug release, and stability studies. The formulation was found to sterile, isotonic, having swelling index 88\% and SEM 100-120 $\mu \mathrm{m}$, particle size $0.765 \mu \mathrm{m}$.with zeta potential- $14.2 \mathrm{mV}$, swelling time was $10 \mathrm{~min}$. The in vitro drug release was found to be over $93.20 \%$ in Simulated Body fluid $\mathrm{pH} 7.4$ at $37^{\circ} \mathrm{C}$ over a prolong period of 5days The formulation was physically and chemically stable at accelerated conditions for period of 1 month.
\end{abstract}

Keywords: anti-emetic, gelatin matrix, cryogelation, injectable suspension

\section{INTRODUCTION:}

The Parenteral route is the most effective and common form of drug delivery system. It is used for which the bio-availability in limited by high first pass metabolism effect of other physicochemical limitation and for drugs with a narrow therapeutic index. Parenteral drug delivery has different technologies that can reduce the total number of injection throughout the drug therapy period. Sustained parenteral drug delivery began to emerge as a clearly designed sub-area of pharmaceutics in the middle of the twentieth century. Development of new sustained release injectable formulation has received considerable attention due to many advantages of these systems such as localized and sitespecific action, prolonged delivery period, decreased drug dosages, reduction of side effects and improved patient comfort and compliance over the conventional parenteral delivery . 1,2

Sustained release injectable formulations are basically designed as microparticles (microcapsules or microspheres), sponges, implants or gel systems. Microparticles are produced by complicated methods. They also suffer from several limitations such as low drug loadings, difficulty in particle size control due to aggregation and difficulty in their reconstitution to initial size. Efficiency of loading methods for active ingredients is limited and a high loading capacity is usually unattainable. A major limitation of implants is the requirement of surgery to remove the system which adds to their costs and risks. Due to these limitations and draw backs many researchers have proposed the use of injectable sponge formulations as substitutes. ${ }^{3}$

Injectable sponge drug delivery system can entrap wide range of drugs and then release them into body over time. It is a unique technology for the novel release of injectable agents and consists of nano or micro porous beads loaded with active agent. After the creation of micro beds or matix, it gets compressed following the compression the sponge gets filled with active agent or medicine and injected into body. Following the injection, the sponge will expand to the original size and shape and start releasing drugs. Sponge or scaffolds have been developed using various techniques such as fiber bonding, gas foaming, microemulsion formation, phase separation, freezedrying, and porogen leaching. More recently, gelation at sub-zero temperatures, known as cryogelation, has been used to create sponge with large interconnected pores. During cryogelation, the reactants are restricted to the unfrozen/semifrozen phases and form a crosslinked network upon polymerization, while the ice 
crystals nucleated from the aqueous phase during freezing function as porogens. The melting of these ice crystals at temperature above the freezing temperature gives rise to interconnected macroporous networks. Injectable sponge drug delivery system which involves use of natural injectable polymers like chitosan, gelatin, sodium alginate, collagen etc.which act as a depot and release the drug in a timely fashion. $., 5,6$

Gelatin is a natural polymer which is biodegradable, nontoxic in nature. Due to its easy process ability and gelation properties, gelatin has been manufactured in a range of shapes including sponges, injectable hydrogels and gelatin microspheres etc. Gelatin sponges or matrices have been utilized for many regional drug delivery systems among the other forms of gelatin. Absorbable gelatin sponge (AGS) was introduced by Correl and Weisman as absorbable hemostatic agent in $1945 .^{7}$

Granisetron hydrochloride $(\mathrm{GH})$ is antiemetic drug, effective both intravenously and orally, acts by antagonizing 5HT3 receptor in the chemoreceptor trigger zone and probably in upper gastrointestinal tract. GH is used in management of nausea and vomiting induced by cytotoxic chemotherapy, radiotherapy and for the prevention of post operating nausea and vomiting. GH has $60 \%$ oral bioavailability due to hepatic first pass metabolism by 7 hydroxilation .Therefore it would be desirable to develop a sustained drug delivery system without this limitation of frequent administration. Recommended dose of $\mathrm{GH}$ is $2 \mathrm{mg} / \mathrm{day}$ twice a day before $30 \mathrm{~min}$ of chemotherapy induced nausea and vomiting for 5-7 days. ${ }^{9}$

The present work was focused on formulation of an injectable sponge of Granisetron Hydrochloride in a gelatin matrix system intended for a 5-day sustained release to be administered in patients suffering from chemotherapy induced nausea and vomiting.

\section{MATERIALS}

Granisetron Hydrochloride was obtained as a generous gift from Wockhardt Research Center (Aurangabad, India). Gelatin was purchased from Lobachemie. (Mumbai, India). Glutaraldehyde was purchased from LobaChemie (Mumbai, India). HPMC K100M was purchased from Otto Chemie, Sodium CMC was purchased from LobaChemie (Mumbai, India). All other chemicals and reagents were of the analytical grade.

\section{METHODS}

\section{Part A] Preparation and Evaluationof Gelatin matrix}

\section{Preparation}

Gelatin was soaked in $100 \mathrm{ml}$ of water for $30 \mathrm{~m}$ to get solution at the varying concentration of $1-6 \% \mathrm{w} / \mathrm{v}$ of gelatin. The drug granisetron HCL (10mg) was added followed by addition of crosslinker glutaraldehyde (0.1-05\%) and then added sustained release polymer HPMC K100M (0.25-2\%). This solution was then stirred vigorously for $10 \mathrm{~m}$ at $1000 \mathrm{rpm}$ using overhead stirrer to form a firm foam. This foam was separated and spread on petri plates and further subjected to process of cryogelation. The process involved drying of gelatin matrix in deep freezer at -10 to $-12{ }^{\circ} \mathrm{C}$ temperature for $24 \mathrm{~h}$ till it formed a dry porous matrix mass .This dry gelatin matrix mass was sifted through 16 \# to get fine brown coloured powder in aseptic condition. Optimised concentration of suspending agent sodium CMC (1\%) was added, the powder was aseptically filled in previously sterilised amber coloured vials $2 \mathrm{ml}$ and then were subjected to sterilization by hot air oven at $140^{\circ} \mathrm{C}$ temperature for 2 h. ${ }^{4,7}$

\section{Optimization study}

A two factor, three levels full factorial design was employed for the optimization of Granisetron HCL gelatin matrix using Design-expert software ${ }^{\circledR} 9.0$ (StatEase, Inc.,USA).The experimental design was applied to study the effect of independent factors such as gelatin concentration and glutaraldehyde concentration on dependent variables i.e. swelling index and pore size

Table 1: Formulation combination as per the $3^{2}$ full factorial designs for Granisetron gelatin matrix.

\begin{tabular}{|l|l|l|}
\hline Formulatio Code & Gelatin \% w/v & GLU (\% v/v) \\
\hline F1 & 6 & 0.1 \\
\hline F2 & 5 & 0.1 \\
\hline F3 & 4 & 0.5 \\
\hline F4 & 4 & 0.3 \\
\hline F5 & 4 & 0.1 \\
\hline F6 & 5 & 0.3 \\
\hline F7 & 6 & 0.3 \\
\hline F8 & 6 & 0.5 \\
\hline F9 & 5 & 0.5 \\
\hline
\end{tabular}

\section{Evaluation of Gelatin matrix}

\section{Appearance}

The appearance and physical characteristics of the gelatin matrix were checked by visual observation and using optical microscope microscopy.

\section{Drug Excipient Compatibility study}

The FTIR spectrum of pure drug and physical mixture in 1:1 ratio were recorded on spectrophotometer for interaction between them by using $\mathrm{KBr}$ pellet method.

\section{Swelling Index}

Swelling index was determined by soaking preweighed pieces $(1 \times 1 \mathrm{~cm})$ of gelatin matrices in double distilled water. Soaked matrices were removed with blunt forceps and blotted to remove excess liquid from the medium at predetermined time $(5,10,15 \mathrm{~m})$ and their weight was determined by using digital weighing balance and \% swelling index was calculated by the following equation. ${ }^{4,5}$

$$
\% \mathrm{~S}=\frac{\mathrm{W} 2-\mathrm{W} 1}{\mathrm{~W} 1} \times 100
$$


Where, $\mathrm{S}$ is the percentage water adsorption of gelatin matrices at equilibrium.

$\mathrm{W} 1$ is the initial weight of the gelatin matrix.

$\mathrm{W} 2$ is the after immersion weight of the gelatin matrix.

\section{Surface scanning study}

Morphological analysis was carried out by a scanning electron microscope (SEM) JEOL model JSM6390LV. Surface morphology of gelatin matrix can be observed by using SEM. Gelatin matrix was mounted on aluminium pin stubs using conductive self-adhesive carbon label. ${ }^{7}$

Part B] Preparation and Characterization of Injectable suspension

\section{Preparation}

Injectable suspension was prepared by reconstitution of formulation. Dry gelatin matrix powder was reconstituted in $2 \mathrm{ml}$ of sterile water for injection (SWFI) at the time of administration to form an injectable suspension

\section{Evaluation of Injectable suspension}

\section{Appearance and pH}

The appearance of formulation was checked by visual observation and $\mathrm{pH}$ of injectable suspension was measured using $\mathrm{pH}$ meter which was previously calibrated using standard buffers of $\mathrm{pH} 4 \& \mathrm{pH} 7$.

\section{Syringeability}

Syringeability of the formulation was assured using 21 to $26 \mathrm{G}$ needles. It was important to assure syringeability of formulation prior to animal study. All prepared formulations were withdrawn into identical 5 $\mathrm{ml}$ plastic syringes placed with 21 to 26 gauge needles to a constant volume $(1 \mathrm{ml})$. The solutions which were easily passed from a particular syringe were termed as pass and the ones which were difficult to pass were termed as fail. ${ }^{8,10}$

\section{Sedimentation Volume}

In sedimentation study, the suspension was transferred to a stoppered measuring cylinder and was stored at room temperature for $24 \mathrm{~h}$. The volume of sediment formed was noted at regular interval of time $(1,3,5,8$ h). 8,10

$$
\text { Sedimentation volume }=\frac{\text { final volume }(\mathrm{Vu})}{\text { Original volume }(\mathrm{VO})}
$$

\section{Swelling Time}

Swelling time was observed visually for gelatin matrix. Dry gelatin matrix powder was added in $2 \mathrm{ml}$ Simulated body fluid (PH 7.2) Time required to swell was determined.

\section{Particle Size and Zeta Potential Measurements}

Formulation was suspended in water and sonicated to form a smooth and uniform dispersion. The particle size and zeta potential of the formulation was obtained using a Malvern particle size analyzer (Mastersizer2000, UK) .4, 8

\section{Drug content estimation}

$0.25 \mathrm{ml}$ of the test formulation was diluted with excess of methanol and evaporated to dryness. The residue was diluted up to $100 \mathrm{ml}$ with mobile phase to get a stock solution of $100 \mu \mathrm{g} / \mathrm{ml}$. From this stock solution, a solution of $40 \mu \mathrm{g} / \mathrm{ml}$ was prepared and analysed by HPLC. ${ }^{14}$

\section{Sterility Testing}

Sterility testing was carried out as per the IP 2014. The formulation was incubated for not less than 14 days at $30^{\circ}-35^{\circ} \mathrm{C}$ in the alternate fluid thioglycolate medium to find the growth of bacteria \& at $20^{\circ}-25^{\circ} \mathrm{c}$ in Soya bean casein digest medium to find the growth of fungi in formulation. The test was performed using positive and negative controls. The bacterial strain used for positive control was Clostridium sporogenes whereas the fungal strain was Candida albicans ${ }^{15}$

\section{In-vitro Drug Release Studies}

In vitro release studies of Granisetron HCL from Injectable gelatin suspension system was performed at $37{ }^{\circ} \mathrm{C}$ using membraneless dissolution model. The dissolution medium was simulated body fluid $\mathrm{pH}$ 7.2. 1 $\mathrm{ml}$ of dissolution medium was withdrawn at specific time intervals and replenished with fresh medium to maintain sink conditions. Orbital shaking Incubator was used to maintain the temperature at $37{ }^{\circ} \mathrm{C}$ and agitated for $30 \mathrm{rpm}$. Aliquots withdrawn were suitably diluted and analyzed using UV spectrophotometer at $302 \mathrm{~nm}^{11}$

\section{Accelerated Stability study}

Stability studies were carried out on optimized formulation according to International Conference on Harmonization (ICH) guidelines. Formulations were filled in vials and subjected to room temperature i.e. at $25^{\circ} \mathrm{C} \pm 2{ }^{\circ} \mathrm{C} / 60 \% \pm 5 \% \mathrm{RH}$ and $40^{\circ} \mathrm{C} \pm 2{ }^{\circ} \mathrm{C} / 75 \% \mathrm{RH} \pm$ $5 \% \mathrm{RH}$ for 1 month. Samples were analysed for appearance, $\mathrm{pH}$ and in vitro drug release. ${ }^{16}$

\section{RESULTS AND DISCUSSIONS}

\section{Optimization study}

The design of experiment (DOE) is an approach in which process variables are first screened and then optimized to determine best settings for the variables. Full factorial design is a quadratic design which requires 3 levels for each factoras.

From the all batches F6 batch was selected that attained the desired swelling index i.e. $88 \%$ and pore size was found to be 11.9 um and was further evaluated. The results of the each experiments performed as per the software are given in Table 2. Empirical relationships between the response and the independent variables have been expressed by the following quadratic model. ${ }^{13}$ 
Table 2: Formulation combination as per the $3^{2}$ full factorial design with responce

\begin{tabular}{|c|c|c|}
\hline $\begin{array}{c}\text { Formulation } \\
\text { Code }\end{array}$ & $\begin{array}{c}\text { Swelling Index } \\
(\boldsymbol{\%})\end{array}$ & $\begin{array}{c}\text { Pore size } \\
(\boldsymbol{\mu m})\end{array}$ \\
\hline F1 & 68 & 5.7 \\
\hline F2 & 78 & 8.7 \\
\hline F3 & 60 & 5.6 \\
\hline F4 & 58 & 3.2 \\
\hline F5 & 50 & 4.3 \\
\hline F6 & $\mathbf{8 8}$ & $\mathbf{1 1 . 9}$ \\
\hline F7 & 71 & 2.5 \\
\hline F8 & 73 & 4.7 \\
\hline F9 & 75 & 9.7 \\
\hline
\end{tabular}

\section{Response Surface plots}

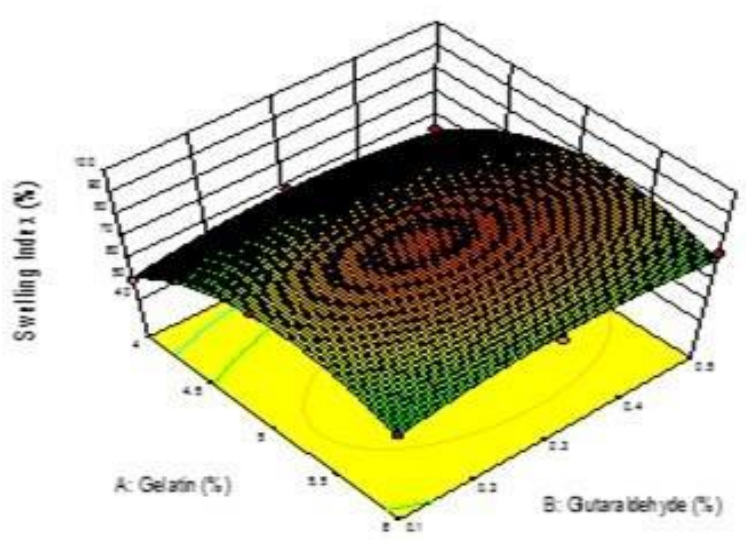

Figure 1: Response surface of swelling index

Swelling Index $=+84.33+8.33 * \mathrm{~A}+1.00 * \mathrm{~B}+0.25 * \mathrm{AB}-$ $18.00 * \mathrm{~A}^{\wedge} 2$

Where, A is concentration of gelatin and $\mathrm{B}$ is Concentration of glutaraldehyde.

Swelling index is the capacity of swelling in body. It is important parameter in injectable sponge preparation and it depends on polymer concentration i.e. gelatin and crosslinking agent i.e. glutaraldehyde.

As shown in figure1 upon increase in concentration of gelatin and glutaraldehyde there is increase in swelling index. It was found that with increase in concentration of gelatin from $4 \%$ to $5 \%$ and of glutaraldehyde 0.1 to $0.3 \%$ swelling index increases but at concentration beyond $5 \%$ to $6 \%$ of gelatin and $0.3 \%$ of glutaraldehyde highly viscous solutions are formed which is difficult to stir and formulate into foam.

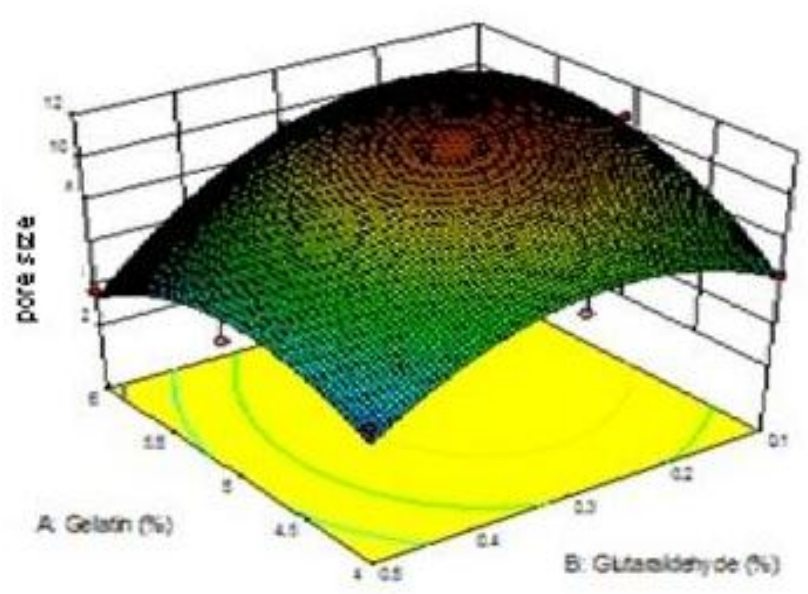

Figure 2: Response surface of pore size Pore size $=+10.99+0.57^{*} \quad \mathrm{~A}+2.05^{*} \mathrm{~B}+1.13^{*}$
$\mathrm{AB}+2.23^{*} \mathrm{~A}^{\wedge} 2-2.78^{*} \mathrm{~B}^{\wedge} 2$

Where, A is concentration of gelatin and $\mathrm{B}$ is Concentration of glutataldehyde.

Glutaraldehyde is a crosslinker which mainly contributes to form a porous matrix of gelatin once it swells in fluid. It was found (figure 2) that with increase in concentration of gelatin from $4 \%$ to $5 \%$ and of glutaraldehyde from 0.1 to $0.3 \%$, pore size increases but at concentration beyond $5 \%$ to $6 \%$ of gelatin and of $0.3 \%$ of glutaraldehyde highly viscous solutions is formed which is difficult to stir and formulate into a foam therefore there was also a decrease in pore size. Thus as per optimization study $0.3 \%$ concentration of glutaraldehyde gives higher pore size.

Contribution of concentration of polymer and crosslinking agent has effect on both the parameters i.e. swelling index andpore size. As the matrix swells in the media it forms porous sponge. The pore size of the sponge entraps the drug and slowly releases the drug. Thus $5 \%$ of gelatin concentration and $0.3 \%$ Concentration of glutataldehyde was selected for further study that gave maximum swelling and pore size of the sponge.

Table 3: Desirability function of optimized formulation

\begin{tabular}{c|c} 
Formulation Code & $\begin{array}{c}\text { Gelatin Concentration } \\
(\% \mathrm{w} / \mathrm{v})\end{array}$
\end{tabular}

F 6
5
Glutaraldehyde
Concentration. $(\% \mathrm{v} / \mathrm{v})$

0.3
Desirability

0.9762
The release is prolonged over the predetermined time period depending upon the concentration of the release retardant HPMC K100M added.
The quality of the fitted model was expressed by the coefficient of determination $\mathrm{R}^{2}$, and its statistical significance was checked by an F-test (analysis of variance) at the $5 \%$ significance level. The statistical 
significance of the regression coefficients was determined by using the t-test (only significant coefficients with $\mathrm{p}$-value $<0.05$ are included). The optimum processing conditions were obtained by using graphical and numerical analysis based on the criteria of the desirability function and the response surface.

Table 4: ANOVA test result

\begin{tabular}{|c|c|c|c|}
\hline \multirow{2}{*}{ SOURCE } & \multicolumn{3}{|c|}{ ABSORBANCE } \\
\cline { 2 - 4 } & $F$-value & $P$-value & $R$-square \\
\hline Quadratic model & 11.61 & 0.0001 & 0.9508 \\
\hline
\end{tabular}

\section{PART A] Evaluation of Gelatin Matrix}

\section{Appearance}

All the formulations were brown colour, brittle matrix powder in appearance. Dry heat sterilization had no effect on physical and chemical properties of the formulation.

\section{Drug Excipient Compatibility study}

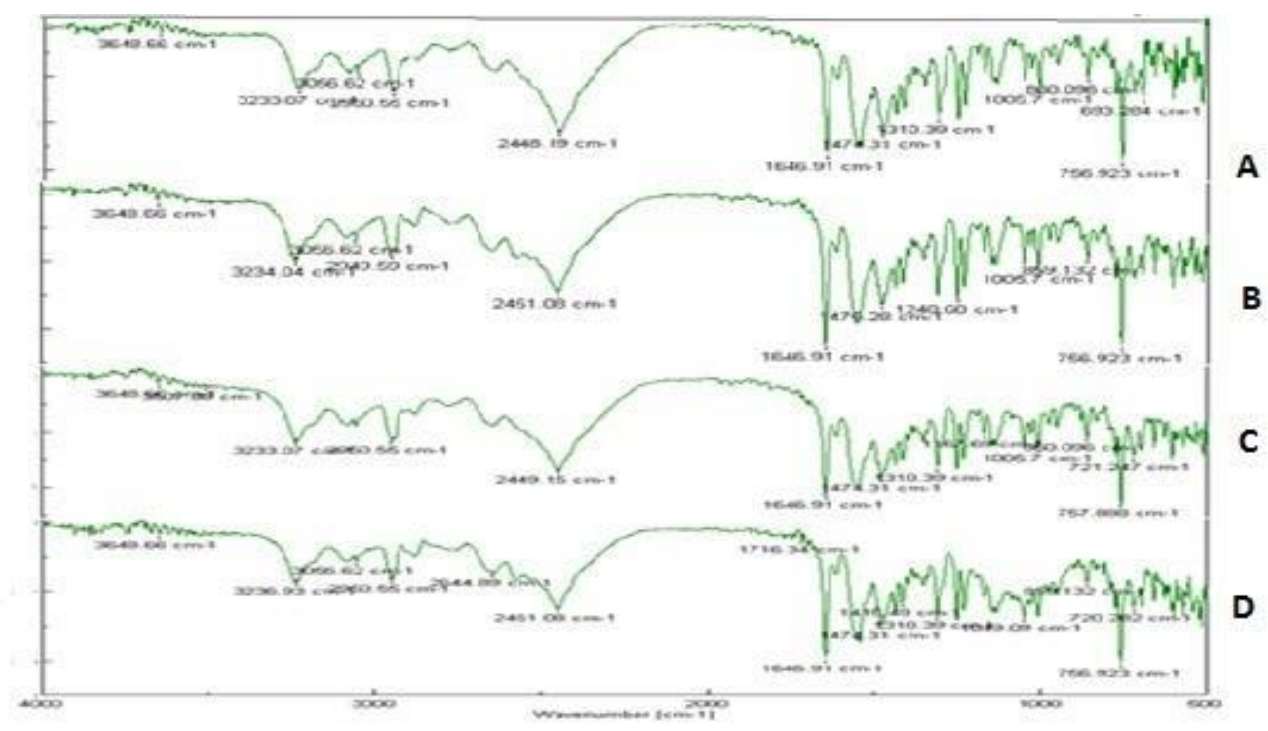

Figure 3: FT-IR Spectra of A) Drug B) Drug + Gelatin C) Drug + HPMCK100M and D) formulation of Granisetron HCL

The FTIR spectrum of pure drug and physical mixture in 1:1 ratio were recorded on spectrophotometer and it shows no any significant change in functional group peak i.e. there was no major interaction between drug and excipients. The characteristic IR absorption peaks of Granisetron HCL and other excipients were at 720$780 \mathrm{~cm}^{-1}\left(\mathrm{C}-\mathrm{H}\right.$ stretch), $2410-2550 \mathrm{~cm}^{-1}(\mathrm{C}-\mathrm{H}=0), 1650$ $1580 \mathrm{~cm}^{-1}(\mathrm{~N}-\mathrm{H}$ bend $), 3400-3200 \mathrm{~cm}^{-1}(\mathrm{~N}-\mathrm{H}$ stretch $)$ present as shown in (figure 3 ) .FTIR spectra of the formulation with polymers showed all the Granisetron HCL characteristics absorption bands suggesting there is no chemical interactions between the drug and polymers used in the formulation. ${ }^{14}$

\section{Swelling Index}

The prepared matrices were subjected to swelling Index which ranged from $50 \%$ to $88 \%$.Swelling index of optimized F6 batch was found to be $88 \%$. It represents the capacity of swelling of matrix in blood. In body gelatin matrix absorbs blood or body fluid and it opens the pores of matrix to gives sustained release of drug over 5 days period. As shown in fig $5 \%$ gelatin concentration has higher swelling property and also gives higher sustained to release of drug.

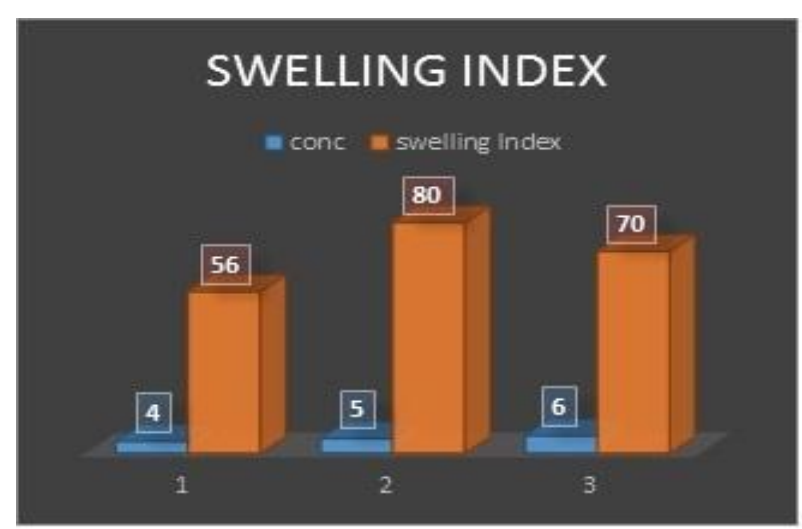

Figure 4: Effect of concentration of polymer on swelling index 


\section{Scanning electron Microscopy}

Scanning electron Microscopy is used to study the microscopic aspects of the formulation. The Gelatin matrix appeared as a very porous and rough structure. The pore size was in the range of 100-120 $\mu \mathrm{m}$. Morphology of gelatin sponge is shown in figure 5 .

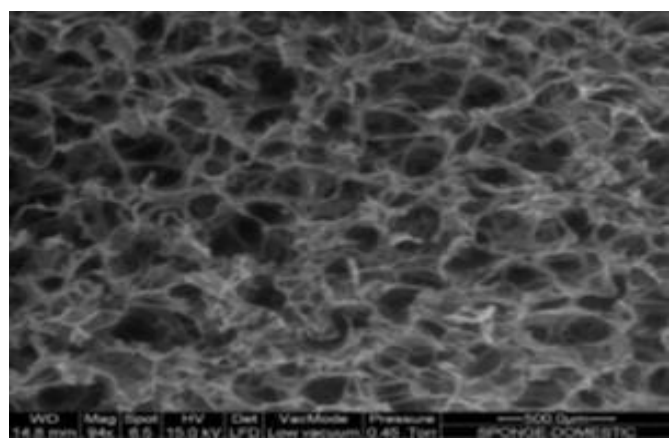

Figure 5: Scanning electron Microscopy of gelatin matrix

\section{B] Evaluation of Injectable suspension-}

\section{Appearance and $\mathbf{p H}$}

All the formulations were dispersed suspension system. The $\mathrm{pH}$ of the all the formulations was found to be between $6.5-7$. The $\mathrm{pH}$ values were found to be in the range tolerated by the subcutaneous tissue. Moreover, the drug was found to be most stable in this $\mathrm{pH}$ range.

\section{Syringeability}

The formulation easily passed through the needle gauge 21. This needle size is suitable for subcutaneous injection.

Table 5: Syringeability of optimized formulation

\begin{tabular}{|c|c|}
\hline Needle gauge no. & Result \\
\hline 21 & Pass \\
\hline 22 & Fail \\
\hline 24 & Fail \\
\hline 26 & Fail \\
\hline
\end{tabular}

\section{Sedimentation study}

The sedimentation volume can have values ranging from less than 1.The sedimentation volume was found to be constant 0.075 for a period of $15 \mathrm{~min}$. The ultimate height of the solid phase depends on the concentration of solid and the particle size.

Table 6: Sedimentation study of gelatin matrix powder

\begin{tabular}{|c|c|}
\hline TIME & Sedimentation volume \\
\hline $\mathbf{5}$ $i n$ & 0.050 \\
\hline $\mathbf{1 0}$ in. & 0.075 \\
\hline $\mathbf{1 5} \mathbf{~ m i n}$ & 0.075 \\
\hline
\end{tabular}

\section{Swelling time}

Swelling time of gelatine matrix was $10 \mathrm{~m}$. It is time required to swell after injecting the reconstituted powder in sterile water for injection and thus formation of sponge in-situ

\section{Particle Size and Zeta Potential Measurements}

Particle size of gelatin suspension was found to be0.7654 um(765.4 d.nm) and Pdl was 0.665. gelatin suspension has good particle size that indicates formulation will easily administered in body and easily passed through blood vessels.

Zeta potential is a measure of surface charge. Zeta potential of formulation was $-14.2 \mathrm{Mv}$ thatmeans gelatin suspension has good physical stability. Zeta Potential determinations can be great value in the development of suspensions, particularly if the controlled flocculation approach is used to formulate.

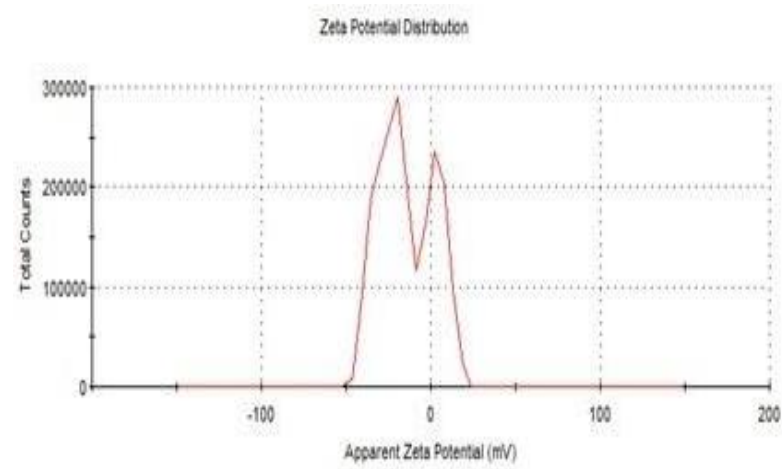

Figure 6: Partic1e Size of gelatin suspension.

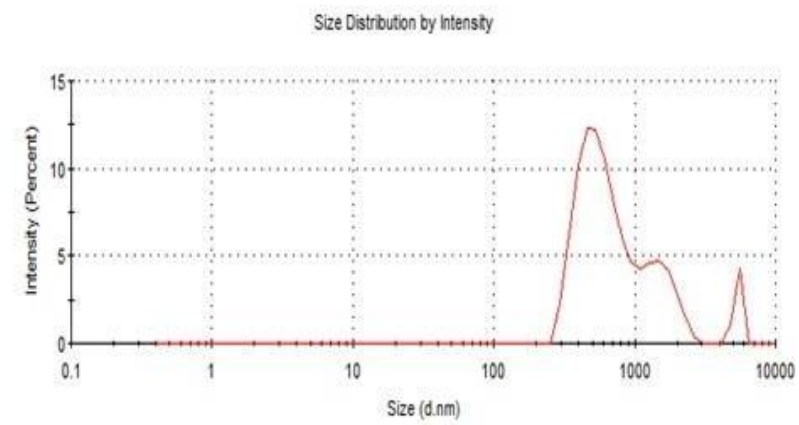

Figure 7: Zeta potential of gelatin suspension.

\section{Drug content estimation}

The percentage drug content in the formulation was calculated and found to be $95.54 \%$ indicating insignificant loss of drug during the formulation.

\section{Sterility testing}

No turbidity was observed in test samples after 14 days. The formulation was found to be free from bacteria and fungi. Hence, it passes the test for sterility as per I.P. The sterility of the formulation may be attributed to aseptic process of preparation and filling the amber colour vials and dry heat sterilization at $140^{\circ} \mathrm{C}$ temperature for $2 \mathrm{~h}$. 
Table 7: Observations for bacterial growth

\begin{tabular}{|l|l|}
\hline Sample & Observation \\
\hline Positive control & Growth \\
\hline Negative control & No growth \\
\hline Test sample & No growth \\
\hline
\end{tabular}

Table 8: Observations for fungal growth

\begin{tabular}{|l|l|}
\hline Sample & Observation \\
\hline Positive control & Growth \\
\hline Negative control & No growth \\
\hline Test sample & No growth \\
\hline
\end{tabular}

\section{In-vitro Drug Release Studies}

In vitro drug release study serve as a comparative tool in formulation and development. Drug release from gelatin matrix into release medium was regulated by dissolution or diffusion of drug, depending upon experimental conditions. In vitro drug release of gelatin matrix formulation was regulated by diffusion mechanism. As the concentration of HPMC K100M increases drug release was retarded. The release on subsequent days was at par with the expected values. About $93.20 \%$ of drug release was observed on the last day which indicated sustenance of the release for 5 days
Table 9: In-vitro Drug Release of formulation

\begin{tabular}{|c|c|}
\hline Time(days) & Cumulative \% Drug release \\
\hline $\mathbf{1}$ & 18.50 \\
\hline $\mathbf{2}$ & 38.35 \\
\hline $\mathbf{3}$ & 57.20 \\
\hline $\mathbf{4}$ & 76.23 \\
\hline $\mathbf{5}$ & 93.20 \\
\hline
\end{tabular}

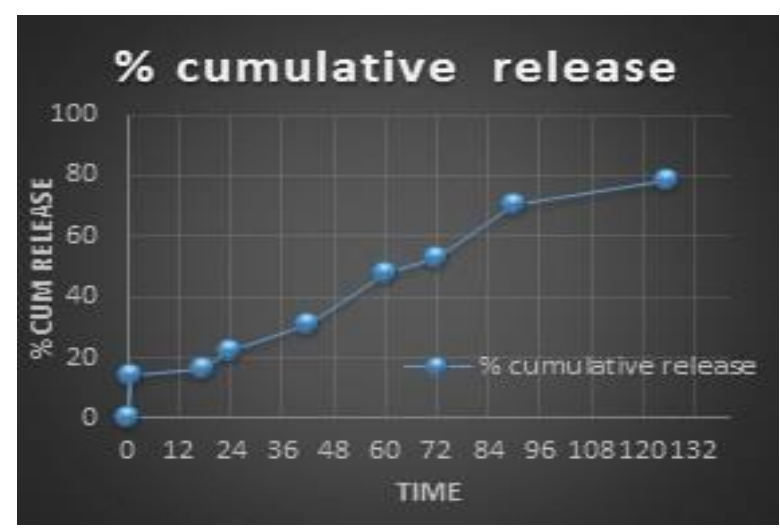

Figure 8: In vitro release profile for optimized formulation

Table 10: Model for release kinetics

\begin{tabular}{|c|c|c|c|c|}
\hline Formulation F6 & Zero order & First order & $\begin{array}{c}\text { Korsemeyer- } \\
\text { Peppas order }\end{array}$ & Higuchi order \\
\hline $\mathrm{R}^{2}$ & 0.972 & 0.893 & 0.984 & 0.975 \\
\hline
\end{tabular}

It is evident from above data (Table 10) that Korsmeyer peppas model was the best fit model for optimized batch. It indicates that the optimized formulation followed non-Fickian diffusion mechanism for drug release.

\section{Accelerated stability study}

Stability studies indicates that formulation F6 was physically and chemically stable at ambient temperature i.e at $25^{\circ} \mathrm{C} \pm 2{ }^{\circ} \mathrm{C} / 60 \% \mathrm{RH} \pm 5 \% \mathrm{RH}$ and at accelerated conditions $40^{\circ} \mathrm{C} \pm 2{ }^{\circ} \mathrm{C} / 75 \% \mathrm{RH} \pm 5 \%$ $\mathrm{RH}$ for a period of 1 month. From stability studies it was observed that the formulation of Granisetron HCL was stable at selected storage conditions in amber coloured vials. It shows no change in appearance, colour, $\mathrm{pH}$, with negligible decrease in vitro drug release.

Table 10: Stability studies results after 1 month

\begin{tabular}{|c|c|c|c|c|}
\hline \multirow{2}{*}{$\begin{array}{c}\text { Formulation } \\
\text { code }\end{array}$} & Storage condition & \multicolumn{2}{|c|}{ Appearance, colour, pH } & $\begin{array}{c}\text { In vitro drug } \\
\text { Release }(\%) \\
\text { after 1 month }\end{array}$ \\
\cline { 2 - 5 } & $\begin{array}{c}\text { Before Reconstitution } \\
\text { of gelatin matrix }\end{array}$ & $\begin{array}{c}\text { After Reconstitution } \\
\text { of gelatin matrix }\end{array}$ & 92.97 \\
\hline \multirow{2}{*}{ F6 } & $\begin{array}{c}\text { Room temperature }\left(25^{\circ} \mathrm{C} \pm\right. \\
2{ }^{\circ} \mathrm{C} / 60 \% \mathrm{RH} \pm 5 \%\end{array}$ & Brown powder & $\begin{array}{c}\text { Dispersed } \\
\text { suspension, } 6.4\end{array}$ & Dispersed \\
& $\begin{array}{c}\text { Accelerated temperature }\left(40^{\circ} \mathrm{C}\right. \\
\left. \pm 2{ }^{\circ} \mathrm{C} / 75 \% \mathrm{RH} \pm 5 \% \mathrm{RH}\right)\end{array}$ & Brown powder,6.3 & suspension, 6.2 & 90.34 \\
\hline
\end{tabular}



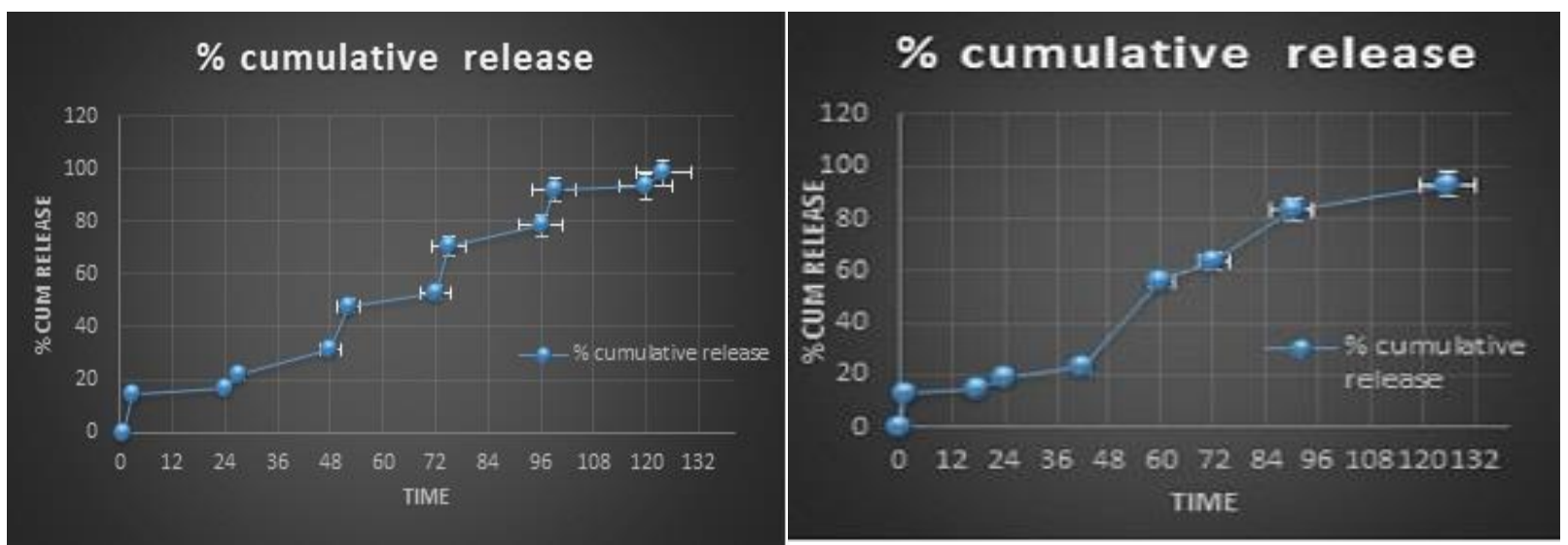

Figure 9: In vitro release after 1 month

\section{CONCLUSION}

The present work was based on the need to reduce the frequency of administration of Granisetron Hydrochloride. It can be concluded that sustainedrelease parenteral formulations are helpful in increasing the efficiency of the dose as well as improving the patient's compliance. Sustained release injectable gelatin sponge formulation Granisetron Hydrochloride of would be advantageous over the prevailing tablets and injections, that require administration every for 12 for 5 days regimen. Injectable gelatin sponge formulations can be anticipated as a promising alternative to conventional oral and parenteral dosage forms. Thus makes easing the practice of medication with an objective to save the valuable life of human being.

\section{ACKNOWLEDGEMENT}

The authors are a grateful to AISSMS College of Pharmacy, Pune, India.

\section{REFERENCES}

1. Wright J, Hoffman A, Historical overview of long acting injections and implants, Springer, 2012; 11

2. Chenite A, Chaput C. Novel injectable neutral solutions of chitosan form biodegradable gels in situ. Biomaterials 2000 ; 21: 2155-2161.

3. Malik K, Singh I, Nagapal M, Arora S. Atrigel A Potential parenteral controlled drug delivery system. Pelagia Research Library, Der Pharmacia sinica. 2010; 1(1):74-81

4. Princely S., Design and evaluation of controlled release gentamycin incorporated gelatine alginate matrices for wound management, Scholars Research Library, 2015, 7 (1):145-153

5. Perry. C, Kusek. K, Injectable Sponge delivers Drug, Cells and Structure, Nov 13,2013

6. David J; Injectable Preformed Scaffolds with Shape Memory Property :1- 6

7. Wei S., Hemostatic absorbable gelatin sponge loaded with 5fluorouracil for treatment of tumors, International Journal Of Nanomedicine; 1499

8. Patel R., a Review on Parenteral Suspension , International Journal of Current Pharmaceutical Research ; Vol 2, Issue 3, 2010

9. Product monograph, Granisetron hydrochloride injection, Omega Laboratories Ltd, 2013; 1-23.

10. Alam A., Formulation and Evaluation of Pharmaceutically Equivalent Parenteral Depot Suspension of Methyl Prednisolone Acetate, Indian J Pharm Sci.; 2009 Jan-Feb; 71(1): 30-34

11. Tiwari S, Saihboomi A. Extended release improving formulation of HPMC matrices. Advancing process solutions pharmaceutical technology Europe. Peer Review. An Advan star publication.2008; 1-8.
12. Ranga $S$, A review on design of experiments (DOE) Review article. Int J of pharm and chemsci.2014; 3(1):26-224.

13. Kalsi PS: Spectroscopy of organic compounds. New age international publishers. Fifth edition: p.60-159.

14. Bhalerao AV, Analysis of Stability of Granisetron Hydrochloride in Nasal Formulations by Stability-Indicating RP-HPLC Method, Research Journal of Pharmaceutical, Biological and Chemical Sciences; Volume 4 Issue 4,Oct Dec, 2013 ;653-662

15. Indian Pharmacopoeia 2014.Government of India ministry of health and family welfare. Published by The Indian pharmacopoeial commission. Ghaziabad, vol-I, 7thedition, 59-66.

16. International conference on harmonization of technical requirements for registration of pharmaceuticals for human use. Stability testing of new drug substances and products $\mathrm{Q} 1 \mathrm{~A}(\mathrm{R} 2) .4^{\text {th }}$ version. 200

*Corresponding Author
Reshma Mirajkar
Department of Pharmaceutics, AISSMS College of Pharmacy,
Near RTO, Kennedy Road, Pune. 411001, Maharashtra,
India Email: reshmamirajkar@gmail.com, Phone. No. -
9422760018

How to cite this article:

Mirajkar R, Jagtap R, Madgulkar A, Formulation of an insitu forming injectable sustained release sponge of granisetron hydrochloride, Journal of Drug Delivery \& Therapeutics. 2016; 6(4):55-62 